\title{
14 AS DIFICULDADES EMOCIONAIS EXPERENCIADAS POR ACADÊMICOS DE ENFERMAGEM NA ABORDAGEM AO PACIENTE1
}

\author{
| Thainá Oliveira Lima²; Claudia de Melo Tavares ${ }^{3}$ |
}

\section{RESUMO}

CONTEXTO: A expressão ou a inibição das emoções depende do desenvolvimento cognitivo e do contexto cultural em que se vive. Sendo assim, o fenômeno educativo não pode ser entendido de maneira fragmentada, mas sim, como uma prática social situada historicamente, que envolve diversos aspectos, principalmente emocionais, que permeiam todo o processo de formação do enfermeiro. OBJETIVO: Discutir junto aos estudantes de enfermagem as dificuldades emocionais experenciadas na abordagem ao paciente. METODOLOGIA: Estudo qualitativo, descritivo e exploratório, realizado com alunos do curso de graduação em Enfermagem, da Escola de Enfermagem Aurora de Afonso Costa da Universidade Federal Fluminense, no estado do Rio de Janeiro, Niterói, Brasil. A coleta de dados se deu através da entrevista em grupo focal. A análise dos resultados foi feita a partir da análise temática de conteúdo. RESULTADOS: conhecer as histórias dos alunos e fazê-los rememorar as situações que julgaram mais marcantes, lhes possibilitou reconhecer as próprias emoções, passo para a construção da Inteligência Emocional, que é capacidade de gerenciar as emoções dentro de nós e em nossos relacionamentos. Em diversas ocasiões os alunos reagem de forma diferente diante dos mesmos acontecimentos. Isto é de grande importância, pois quer dizer que boa parte de nossas ações não estão nos estímulos externos, e sim em condições pessoais, que podem ser conscientes ou inconscientes.

CONCLUSÃO: foi possível dar visibilidade às experiências de dificuldade emocionais vivenciadas pelos estudantes de enfermagem e, assim, propor mudanças e abertura de novos espaços de discussão no ambiente universitário.

\section{PALAVRAS-CHAVE: Emoções; Enfermagem; Inteligência emocional; Educação em enfermagem}

\section{RESUMEN}

\section{"Dificultades emocionales de los estudiantes de enfermería en la aproximación al paciente"}

CONTEXTO: La expresión o inhibición de las emociones depende del desarrollo cognitivo y del contexto cultural en el que vivimos. Así, el fenómeno educativo no puede entenderse de manera fragmentada, sino como una práctica social, históricamente situado, lo que tiene muchas implicaciones, sobre todo emocionales, que impregnan todo el proceso de formación en enfermería.

OBJETIVO: Discutir junto a los estudiantes de enfermería dificultades emocionales experimentadas en el abordaje del paciente.

METODOLOGÍA: Estudio cualitativo, descriptivo y exploratorio realizado con estudiantes de grado en Enfermería de la Escuela de Enfermería de la Universidad Federal Fluminense Afonso Costa Aurora en el estado de Río de Janeiro, Niterói, Brasil. La recogida de datos se llevó a cabo a través de grupo de entrevista. El análisis se realizó a partir del análisis de contenido temático.

RESULTADOS: Conocer las historias de los estudiantes y inducirlos a recordar las situaciones que consideren más destacadas, les permitirá reconocer sus emociones, paso a la construcción de la inteligencia emocional, que es la capacidad de manejar las emociones en nosotros y en nuestras relaciones. En varias ocasiones, los estudiantes reaccionan de manera diferente a los mismos hechos. Esto es de gran importancia, porque significa que la mayoría de nuestras acciones no son espoleadas por estímulos externos, pero en las condiciones personales, que pueden ser conscientes o inconscientes.

CONCLUSIÓN: Es posible hacer visible la dificultad emocional experiencias de los estudiantes de enfermería y así proponer cambios y la apertura de nuevos espacios para la discusión en el ámbito universitario.

DESCRIPTORES: Emociones; Enfermería; La inteligencia emocional; Educación en enfermería

\section{ABSTRACT \\ "Emotional difficulties experienced by nursing students in the approach to patients"}

BACKGROUND: The expression or inhibition of emotions depends on the cognitive development of the cultural context in which we operate. Therefore, the educational phenomenon cannot be understood as fragmented, but like a social practice which involves various aspects, especially emotions, which are a vital part of the entire nursing training process. OBJECTIVE: To discuss with students the emotional difficulties experienced when approaching patients.

METHODS: Qualitative, descriptive study, conducted with graduation students of Escola de Enfermagem Aurora de Afonso Costa from Universidade Federal Fluminense, on Rio de Janeiro state, Brazil. Data collection was carried out through focus group interview. The analysis was made from the thematic content investigation.

RESULTS: To know stories of these students and make them recall situations they deemed most outstanding and that will enable them to recognize their own emotions, a step in the construction of Emotional Intelligence, which is the ability to manage emotions within ourselves and in our relationships. On several occasions, students react differently to the same events. This is of great importance, since it means that most of our actions are not triggered by external stimuli, but by personal conditions, which may be conscious or unconscious.

CONCLUSION: It was possible to make difficult emotional experiences of nursing students visible, and thus propose changes and the opening of new spaces for discussion in the university environment.

\section{KEYWORDS: Emotions; Nursing; Emotional intelligence; Nursing educationh}

Submetido em 18-04-2016

Aceite em 10-09-2016

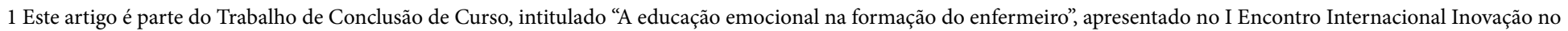
Ensino na Saúde e Enfermagem.

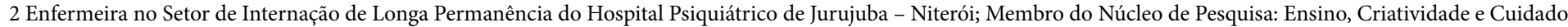
em Saúde e Enfermagem; Mestranda em Ciências do Cuidado em Saúde pela Universidade Federal Fluminense, Niterói, RJ, Brasil, oliveira.thina@hotmail.com

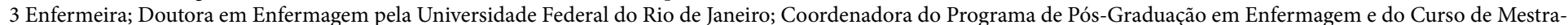

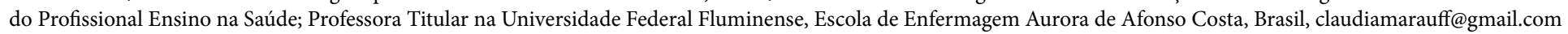




\section{INTRODUÇÃO}

As emoções servem para estabelecer a nossa posição no confronto com o meio ambiente e levam-nos ao encontro de certas pessoas, estratégias de ação e ideias, enquanto, ao mesmo tempo, nos afastam de outras. A expressão ou a inibição das emoções depende do desenvolvimento cognitivo do indivíduo e do contexto cultural em que vive (Cunha, 2013).

Assim, o fenômeno educativo não pode ser entendido de maneira fragmentada, ou como uma abstração válida para qualquer tempo e lugar, mas sim, como uma prática social situada historicamente numa realidade total, que envolve aspectos valorativos, culturais, políticos, econômicos e principalmente emocionais, que permeiam a todo o processo de formação do enfermeiro (Schafranski, 2005). Manejar os impulsos negativos emocionais como ansiedade, frustração, raiva e tristeza fazem com que as pessoas tenham foco para incorporar o autoconhecimento, a autoconsciência e empatia, trazendo benefícios mensuráveis até para a qualidade de vida e a produtividade.

Quem demonstra "controle emocional", autoestima elevada e autoconfiança têm capacidade para identificar muitas soluções para os problemas enfrentados no diaa-dia. É notório, por exemplo, que administrar conflitos é uma das competências que mais exige o uso da habilidade ou capacidade emocional, uma vez que no ato de uma negociação a pessoa demonstra, ou não, equilíbrio entre razão e emoção. As duas capacidades emocionais se complementam, pois técnica, experiência e visão são fundamentais, porém tudo isso se torna poderoso quando aliado à Inteligência Emocional (Pizzol, 2013). A orientação moderna para o sucesso profissional pressupõe que os indivíduos saibam criar condições onde se sintam seguros, motivados, satisfeitos e confortáveis para enfrentar os desafios requeridos por suas realizações pessoais frente ao mesmo. A inteligência emocional está relacionada com o uso inteligente das emoções, inclusive nos aspectos relacionados ao trabalho. Afinal, para efetuá-lo, uma pessoa é envolvida em todos os seus aspectos, inclusive psicológicos. Dessa maneira, as emoções inevitavelmente interferem na maneira do indivíduo executá-las, contribuindo tanto para a satisfação quanto para a insatisfação pessoal. (Gomes, 2013). Diante disso, fica evidente a necessidade de adoção de medidas para uma qualificação adequada dos estudantes da graduação de enfermagem.
É preciso capacitar emocionalmente as pessoas que futuramente irão trabalhar no cuidado direto e indireto de outras pessoas, pois a capacitação acadêmica no sentido das habilidades técnicas, já é oferecida pela graduação. Além de melhorar a qualidade das relações, a educação emocional evita desgastes biológicos, evitando o aparecimento de doenças mentais e psicossomáticas. $\mathrm{O}$ desenvolvimento da inteligência emocional na graduação é essencial para a prosperidade, senão para a sobrevivência da profissão de enfermagem. Sendo assim, o objetivo do estudo é discutir junto aos estudantes de enfermagem as dificuldades emocionais experenciadas na abordagem ao paciente.

\section{METODOLOGIA}

A abordagem metodológica utilizada neste estudo foi qualitativa, do tipo descritivo- exploratória. Para atender a necessidade da pesquisa, utilizou-se como campo de estudo a Escola de Enfermagem Aurora de Afonso Costa (EEAAC), pertencente à Universidade Federal Fluminense (UFF), Niterói, estado do Rio de Janeiro, Brasil. A escolha deste local visou contribuir para a melhoria da educação emocional dos estudantes da instituição em que atuamos. Os participantes desta pesquisa foram dez estudantes do curso de graduação. Como critérios para inclusão, estabeleceram-se: graduandos do $9^{\circ}$ período (alunos que cursaram a maior parte das disciplinas teóricas e práticas da graduação), alunos regularmente matriculados no curso, e que aceitaram participar da pesquisa assinando o termo de consentimento livre e esclarecido. Como critério de exclusão: alunos ouvintes e transferidos de outras instituições. A técnica para a coleta de dados foi a da entrevista em grupo focal. O grupo ocorreu no mês de outubro/2014, durante a realização do grupo os alunos puderam responder livremente as questões do roteiro ("Já passou por alguma experiência que teve dificuldade emocional na abordagem ao paciente? Se sim, qual? Você recebeu orientações sobre como lidar com suas emoções em algum momento do curso de graduação em enfermagem? Se sim, em qual momento ou disciplina ocorreu? Quais foram? De que forma elas te ajudaram?"), o grupo teve duração de uma hora e trinta minutos. Os dados foram submetidos à análise temática de conteúdo e discutidos com conceito de Inteligência Emocional (Goleman, 2012) e de Educação Emocional de Casassus (2009). 
Para resguardar o anonimato dos participantes, os depoimentos nesse estudo foram identificados com base na adjetivação dos nomes das emoções. Pesquisa aprovada pelo Comitê de Ética em Pesquisa: 000.783.975 (CAAE: 33728014.0.0000.5243).

\section{RESULTADOS}

Os resultados da pesquisa estão dispostos abaixo através do Perfil Sócio-Demográfico dos Participantes e Descrição das Experiências de Dificuldade Emocional na Abordagem ao Paciente, apresentadas nas seguintes categorias de análise: As dificuldades emocionais associadas às situações pré-existentes dos graduandos; $\mathrm{O}$ professor e as dificuldades emocionais dos alunos no ensino teórico-prático; as dificuldades emocionais associadas ao envolvimento emocional dos alunos no ato de cuidar.

\section{Perfil Sócio-Demográfico dos Participantes do Es- tudo}

O estudo contou com o total de 10 graduandos. Em relação ao sexo, $100 \%$ dos participantes eram do sexo feminino. Em relação à idade, 5 estudantes tinham idade inferior a 25 anos (50\% dos alunos), 4 estudantes com idade entre 25 e 30 anos ( $40 \%$ da amostra) e 1 estudantes com idade superior a 30 anos (10\%). De acordo com quem residiam, 6 estudantes ( $60 \%$ dos estudantes) moravam com a família (pais e irmãos), 2 estudantes (20\% dos graduandos) com companheiro (cônjuge) e outros 2 alunos (20\%) sozinhos. Sobre a situação conjugal, 8 alunos ( $80 \%$ da amostra) encontravam-se solteiros, 1 estudante (10\%) casado e 1 estudante (10\%) em união estável. A renda mensal era de 1 salário mínimo para 1 estudante ( $10 \%$ dos participantes), de 2 a 3 salários mínimos para também 1 aluno (10\%) e acima de 3 salários mínimos para 8 estudantes ( $80 \%$ dos alunos).

Pode-se perceber que este estudo em sua totalidade contou com participantes do sexo feminino. Isto se deve ao fato da profissão de enfermagem ser predominantemente feminina, por socialmente estar associada a aspectos maternais, de sensibilidade, de afetividade e de cuidado.

Este é um dado importante, pois a mulher em suas características naturais tende a ser mais emotiva do que o homem, expressando suas emoções e muitas vezes podendo fazer uso delas para a compreensão das necessidades alheias (necessidades dos pacientes).
Outro dado que merece destaque, é a idade dos alunos; a maioria dos estudantes têm menos de 25 anos, o que contribui de certa forma para a imaturidade emocional, uma vez que, por conta da pouca idade, muitos podem não ter vivenciado experiências para tal maturidade. $\mathrm{O}$ fato de residirem com os pais, é outro aspecto que pode contribuir para imaturidade emocional, visto que, os alunos que moram sozinhos tendem a acumular responsabilidades, sendo muitas vezes obrigados a administrar os afazeres diários e até mesmo os aspectos emocionais. O salário mínimo acima de 3 para $80 \%$ dos alunos é um aspecto positivo, pois dificuldade financeira é outra questão que pode contribuir de forma negativa para a estabilidade emocional.

\section{Descrição das Experiências de Dificuldade Emocio- nal na Abordagem ao Paciente}

Neste momento os alunos são questionados sobre suas experiências durante o estágio curricular. Em seguida, os alunos descrevem através das falas as situações nas quais tiveram dificuldades emocionais na abordagem ou procedimentos realizados com os pacientes.

\section{As dificuldades emocionais associadas às situações pré-existentes dos graduandos.}

Nos depoimentos abaixo podemos evidenciar que a expressão das emoções dos alunos de enfermagem, quase sempre esteve relacionada a algum evento ou situação pré-existe, principalmente ao que tange aos aspectos familiares. Também é possível perceber como situações aparentemente parecidas desencadeiam emoções distintas.

Quando eu estava no $6^{\circ}$ período em DIP (Doença Infecciosa e Parasitária) eu passei pelo momento da minha vida que eu descobri que a minha mãe estava doente. Tinha uma paciente que não se mexia, e quando me colocavam para falar com ela, aquilo acabava comigo. Eu não tinha estrutura emocional para chegar ali e falar com aquela paciente, interagir com ela, eu não conseguia aquilo me bloqueava. Eu falava assim: Pelo amor de Deus professora, faz tudo, me deixa com todos os pacientes, mas não me deixa com essa paciente, eu não tinha estrutura emocional porque eu já saía de casa com aquilo, eu sabia que aquela pessoa poderia ser a minha mãe. E. P. Confiante (comunicação pessoal, Outubro 15, 2014). 
Eu também passei por uma situação em ESAI (Enfermagem na Saúde do Adulto e do Idoso) quando... No meu primeiro semestre de monitoria, eu estava no $6^{\circ}$ período, meu pai tinha acabado de falecer, tinha pouco tempo e eu lembro até hoje que era a "fulana" que estava comigo lá no setor e tinha um paciente lá que era igualzinho ao meu pai. Ele tinha feito uma cirurgia. A filha dele estava lá pegando na mão dele e tudo, e eu lembro que quando fui perguntada se podia ficar com aquele paciente eu respondi - claro não tem problema não. Quando eu cheguei lá e vi que ele era igual ao meu pai eu comecei a chorar. A professora veio e disse assim: o que aconteceu? Eu falei não, eu não estou conseguindo, eu não estou conseguindo! A professora falou - calma respira e eu não consegui falar com ela, eu não conseguia controlar minhas emoções, todo mundo no setor olhando pra mim e eu não consegui de jeito nenhum... Ela falou você quer mudar de paciente? Eu falei não, ela disse você não quer mudar de paciente? Eu falei não, eu tenho que aprender a controlar isso, porque sempre quando eu me deparar com essas coisas eu não vou fazer? Não, eu tenho que saber me controlar. Só sei que eu fiquei com aquele paciente do início ao fim, chorando, mas fiquei. Depois no outro dia eu voltei e graças a Deus não senti mais nada. D. B. Terna (comunicação pessoal, Outubro 15, 2014).

Os depoimentos expressam o quanto os alunos são atingidos por processos de transferência quando se encontram cuidando. Não são raras as situações em que se defrontam com pessoas e situações que lhes remete a contextos pessoais e familiares.

\section{O professor e as dificuldades emocionais dos alunos no ensino teórico-prático.}

Muitas situações imprevisíveis podem ocorrer no momento do aprendizado prático. Nem todas as experiências podem ser conhecidas, e até mesmo monitoradas pelo professor. Como preparar-se para enfrentar essas situações? As falas a seguir permitem esta reflexão.

Foi assim, eu peguei uma paciente de pneumo, ela estava entubada, estava com uma gastrostomia só que com sonda vesical, de foley, e era banho no leito e ela era toda atrofiadinha, a gente foi dar banho nela e quinto período você não viu nada ainda... Eu e a minha dupla seguimos o banho, a sonda soltou da gastro e eu não sabia o que fazer, eu fiquei desesperada pedindo ajuda para a equipe, e a equipe simplesmente botou a culpa na gente. Não sabia o que fazer e a médica fechou a cara para gente. E eu vou fazer o que?
E tipo naquela situação, eu nunca tinha passado por isso, a gente terminou o banho limpamos tudo e tudo mais... E eu fiquei com um peso sabe, parece que tudo veio para cima de mim, me senti tão mal que sai da enfermaria depois que fiz tudo, prestei cuidados integrais a ela nem tinha terminado o estágio ainda e fui lá pra fora e comecei a chorar. A professora foi atrás de mim e começou a conversar comigo e eu chorando, e ela perguntou: porque você está chorando? E eu não soube explicar o que eu estava sentindo, mas me senti mal diante daquilo. Não era algo proposital, tanto que eu não gosto da clínica médica feminina, não suporto aquele lugar porque aquela equipe me traumatizou, porque a equipe ao invés de me ajudar não... Nesse dia a professora falou para eu ir embora, descansar, ir pra casa... Mas eu não sei explicar o que eu senti, mas foi um peso, um mal estar [...] T. M. Triste (comunicação pessoal, Outubro $15,2014)$.

ESAI (Enfermagem na Saúde do adulto e do Idoso) é um divisor de emoções! (Risos) T. S. Ansiosa (comunicação pessoal, Outubro 15, 2014).

Exatamente, só que eu era o que? Acadêmica não entendia nada... E tipo é engraçado que mexe muito com você cara... Eu não consegui prestar mais cuidados a ela, diante disso eu não soube lidar, eu não enfrentei, eu acho que hoje seria diferente até porque a gente está se formando, mas tinha acabado de sair de fundamentos estava cruazinha ainda, nem tinha feito esses acadêmicos que eu fiz. T. M. Triste (comunicação pessoal, Outubro $15,2014)$.

Comigo foi em fundamentos na época, na sala de vacinação, tinha aplicado a vacina só que na hora de desprezar a seringa eu desprezei no lugar errado, na frente da paciente a professora chamou minha atenção e a paciente ficou completamente nervosa, achando que eu tinha feito errado e eu disse não calma o procedimento eu fiz certo só que o erro foi meu na hora de desprezar, na hora eu fiquei muito nervosa, mas consegui sair mais ou menos bem. Fui para casa muito mal, pensando: eu não quero mais isso! Revoltada... D. S. Inquieta (comunicação pessoal, Outubro 15, 2014).

O discurso acima aponta para a necessidade e importância do professor apoiar e incentivar uma postura de segurança emocional da discente.

\section{As dificuldades emocionais associadas ao envolvim- ento emocional dos alunos no ato de cuidar.}

Através das descrições abaixo, fica evidente não só a dificuldade para lidar com as situações, mas a dificuldade emocional está atrelada ao envolvimento emocional dos alunos em certas ocasiões no ato de cuidar dos pacientes. 
Eu já tive experiências iguais, de chorar de me emocionar, porque eu também sou muito emotiva, mas agora a pouco tempo na monitoria de Gerencia 1, eu estava no Carlos Antonio com o pessoal e uma mãe que tem problemas psicológicos, faz tratamento enfim, ela já tem três filhos e agora com essa criança que está com quadro de desnutrição. A criança já estava dois meses sendo acompanhada pelo posto e ela não conseguia ganhar peso nenhum, nenhum, inclusive ela até perdeu. A médica foi falar com essa mãe perto da gente (eu como monitora e os alunos), se essa mãe não criasse alguma forma de melhorar o quadro dessa criança, que a criança poderia vir... Ela não falou em questão de morte, mas a mãe ainda falou: você tá querendo dizer que a minha filha vai morrer? Ela respondeu não, mas se você não cuidar dela é o que pode acontecer, ela pode ter algum problema cardíaco... E a mãe falava o tempo todo assim: ninguém tira a vida não, só Deus e a médica meio que se estressou e eu fui tentar conversar com a mãe. Eu falei - mãe ela precisa de você, ela precisa seguir uma dieta, passar pela nutricionista... A mãe virou para mim e falou assim: você tem filho? Eu falei não, a mãe disse: então pega ela pra você. Na hora eu estava com muita pena daquela criança, mas a minha emoção foi de raiva, de muita raiva, sabe? A criança não tem nada com isso. $\mathrm{E}$ eu falava - ela é sua filha e ela precisa de você, entende? É você quem tem que cuidar dela... Mas a mãe renegava a filha o tempo todo, meu sentimento foi de muita raiva, e não suportava as coisas que ela falava [...] J. M. Temerosa (comunicação pessoal, Outubro 15, 2014).

Ah, me deixa falar uma coisa que aconteceu. Está até aqui no celular, essa semana uma paciente lá do DIP (Doenças Infecciosas e Parasitárias), estágio curricular, que é usuária de droga, HIV positivo de transmissão vertical, tem câncer e foi renegada pela mãe, fugiu. Ela foge, ela evadiu-se do hospital por duas vezes só essa semana, vai embora e volta no dia seguinte, e o que a gente faz? Ela gosta de escrever, desenhar, e ela é um ano mais velha que eu e me chama de tia. E pra gente tentar manter ela lá a enfermeira do plantão deu um conjunto de canetinha para ela e eu uma lição; escrever sobre a equipe de enfermagem, escrever sobre o setor e ela escreveu. Não dá para ler a carta porque é bem grande, mas eu vou mostrar o desenho só, que ela fez, está aqui no celular, ela além de ter feito a carta muito bonita ela fez esse desenho escrito: tudo posso naquele que me fortalece, o nome dela e eu amo vocês. E a carta dela é essa aqui, frente e verso e está pendurada no mural do DIP para que toda a equipe possa ler.
Assim a gente tem um misto de pena, tristeza quando ela vai embora, de raiva e felicidade quando ela volta. Vamos embora! Segura! Vamos terminar esse tratamento! Ela volta para tentar se tratar mais uma tentativa, e é uma mistura de emoções. D. B. Terna (comunicação pessoal, Outubro 15, 2014).

Teve uma vez que assim, não era nem eu que estava com essa paciente, acho que foi em ESAI (Enfermagem na Saúde do Adulto e do Idoso), eu não lembro porque eu fui até o leito dela, ver o que estava acontecendo... A paciente tinha acordado de uma cirurgia de amputação da perna, ela tinha acordado desesperada e ela chorava dizendo o que eu vou fazer da minha vida? Como é que eu vou trabalhar? E a minha vontade era sentar do lado dela e chorar e dizer: realmente o que você vai fazer da sua vida? Como é que você vai trabalhar? Eu não tinha estrutura nenhuma para lidar com aquilo ali, nenhuma, nenhuma mesmo, a vontade era de se juntar a ela e chorar junto e seria a melhor coisa que eu poderia fazer naquele momento... Eu quis sair de perto, me afastei, já não era minha paciente mesmo e dei graças a Deus por isso... (Risos). E me afastei. U. S. Alegre (comunicação pessoal, Outubro 15, 2014).

Em função da idade jovem, muitos dos alunos não tiveram tempo de vivenciar formas de processar e lidar com o sofrimento, e muitas vezes isso ocorre no momento do cuidar, em ambiente hospitalar.

\section{DISCUSSÃO}

Ao conhecer as diferentes situações vivenciadas pelos estudantes podemos também avaliar a questão da Competência ou Incompetência Emocional proposta por Juan Casassus, que demonstra como agimos em relação ao enfrentamento e reconhecimento das nossas emoções, para que a partir disso, possamos estar aptos à Educação Emocional, ou seja, um conjunto de habilidades que o indivíduo adquire para auxiliar no desenvolvimento das suas emoções e sentimentos, ensinando-o a manifestá-las de uma maneira melhor, orientando na questão do autocontrole sobre o comportamento emocional (Casassus, 2009). Podemos ver em diversas ocasiões, que as pessoas reagem de formas diferentes diante dos mesmos acontecimentos externos. Por isso, podemos dizer que acontecimentos não determinam, mas disparam reações diversas em pessoas diversas, e que as emoções são disparadas por avaliações cognitivas de acontecimentos externos. Essa distinção é de grande importância, pois quer dizer que a explicação de boa parte de nossas ações não está nos estímulos externos, e sim em nossas condições pessoais, que podem ser conscientes ou inconscientes (Casassus, 2009). 
Isto é perceptível na primeira categoria, na qual os depoimentos das alunas expressam sua capacidade de lidar, ou não, com as emoções diante de processos semelhantes aos vivenciados em família. No primeiro depoimento a aluna não consegue enfrentar suas emoções, porém no segundo, mesmo com a dificuldade emocional, a aluna consegue reconhecer suas emoções e contornar/enfrentar a situação que remete ao adoecimento familiar. Sendo assim, ao invés de nos limitarmos a sentir que são as emoções que nos atinge, devemos nos aproximar do que sentimos nos avizinhando de nossas emoções. Iniciaremos assim uma relação com uma emoção, com a aceitação da experiência emocional que se tem. Podemos, então, sentir um suporte ou um apoio que nos permita manter essa relação e não precisaremos negar o que sentimos (Casassus, 2009).

Já na segunda categoria fica evidente a necessidade de preparo docente para auxílio das emoções dos alunos, no segundo depoimento destaca-se o nervosismo da aluna diante da forma como é chamada a atenção pela professora, o que configura falta de orientação da academia para com o docente ao que tange tais situações. Deste modo, o docente de enfermagem precisa estar aberto às mudanças em sua forma de trabalhar, apesar das dificuldades que nascem em meio a uma quebra de paradigmas; precisa, também, estar atento às metodologias ativas e às novas práticas pedagógicas, que extrapolam o simples repasse de informação/conteúdo. É essencial priorizar a troca de construção de conhecimento de cada um, assim como a escuta e o acolhimento nas relações, para que os futuros profissionais possam comungar com uma prática profissional humanista (Araújo e Vieira, 2013). Além disto, corrigir publicamente uma pessoa é o primeiro pecado capital da educação. Um educador jamais deveria expor o defeito de uma pessoa, por pior que ele seja, diante dos outros. A exposição pública produz humilhação e traumas complexos difíceis de serem superados. Um educador deve valorizar mais a pessoa que erra do que o erro da pessoa (Cury, 2003).

A partir da terceira categoria podemos levantar os seguintes questionamentos: "Quantas emoções circulam no processo de aprendizagem de cuidar de enfermagem? Como desenvolver competências sócioemocionais? Apenas através da experimentação e exposição ao risco emocional? ". Com base nos depoimentos, fica notória a necessidade de preparo e também do desenvolvimento de espaços de supervisão, e escuta das emoções vivenciadas pelos aprendizes do cuidar.
A aprendizagem centrada no aluno tem como premissa principal permitir a participação ativa do discente no seu processo de aprendizado que envolve seu crescimento pessoal e profissional e tem como pressuposto a ideia de que a colaboração docente-discente melhora a eficácia da ação docente (Araújo e Vieira, 2013). Nesse contexto, o adequado preparo emocional, e mesmo simulações ou estudo de situações-problemas como forma de preparo para entrada no cenário hospitalar se torna necessário e imprescindível.

A educação problematizadora mostra-se como uma forma de vialibilizar questões referentes ao ensino. Dentre as várias propostas de metodologias ativas, a problematização tem sido muito utilizada como estratégia, uma vez que estimula a participação do educando, desenvolvendo sua autonomia e sua compreensão da responsabilidade individual e coletiva no processo de aprendizagem (Giannini e Afonso, 2012).

Sendo assim, é importante que o docente esteja atento a essas novas possibilidades e procure se adequar as novas exigências de ensino e aprendizagem impostas ao seu processo de trabalho.

De acordo com Assad e Viana (2003), a partir da experiência pessoal, entendemos que a formação do enfermeiro atuante na área hospitalar está diretamente relacionada à sua experiência assistencial. Os resultados do processo formativo podem ser mais ou menos fecundos, de acordo com a intensidade e fundamentação teórica, que alicerça a reflexão sobre as ações. Quando são sistemáticas, intensas e críticas, facilitam avanços no sentido de conhecer a si mesmo e ao ambiente que o cerca, desenvolver o poder de argumentação, a capacidade de equilibrar teoria e prática e, finalmente, intercambiar experiências com a equipe e com suas emoções.

Conhecer estas histórias e fazê-los rememorar as situações que julgaram mais marcantes, lhes possibilitou identificar/reconhecer as próprias emoções, passo número um na construção da Inteligência Emocional, que é [...] capacidade de identificar nossos próprios sentimentos e os dos outros, de motivar a nós mesmos e de gerenciar bem as emoções dentro de nós e em nossos relacionamentos (Goleman, 2012). 


\section{CONCLUSÃO}

Este estudo possibilitou a identificação de experiências de dificuldade emocional vivenciadas pelos estudantes de enfermagem da Universidade Federal Fluminense. Foi possível dar visibilidade a tais situações e assim propor mudanças e abertura de novos espaços de discussão e interação do tema ao ambiente universitário.

Através da análise dos depoimentos, foi possível perceber a inexistência de orientação sobre as emoções na graduação por parte dos docentes, não que estes sejam culpados por isto, pois não há no currículo um conteúdo uma disciplina ou atividade que aponte para este tema, e nem mesmo uma perspectiva acadêmica que considere essa abordagem de forma transversal e contínua. É possível dizer que ainda não se teve a dimensão da importância deste assunto na academia, e este trabalho busca justamente isto, dar notoriedade ao tema e, talvez, propor uma mudança no currículo que inclua a educação emocional na graduação de enfermagem.

Analisar as estratégias adotadas pelos alunos diante do sofrimento emocional é fundamental para nos aproximarmos de nossa própria condição humana, que se escutada, refletida e comparada com outros contextos podem ajudar muito no processo de ressignificação da dor e do desenvolvimento de uma atitude acolhedora diante da dor do outro e porque não da nossa própria dor, já que fazemos parte do gênero humano.

Considera-se que estudos como este contribuem para uma análise ampliada das questões que envolvem a formação do enfermeiro. Acredita-se que é possível contribuir com parâmetros que norteiem o processo ensinoaprendizagem e dar, através desta pesquisa, visibilidade a questões que não são discutidas no ensino da enfermagem.

\section{IMPLICAÇÕES PARA A PRÁTICA CLÍNICA}

Reconhecer a importância da habilidade emocional do enfermeiro para lidar com os pacientes se faz necessário para manter uma abordagem na assistência de enfermagem que contemple empatia, inteligência emocional e autoconhecimento, para que assim as emoções que irão emergir de situações da prática profissional, não sejam capazes de influenciar de forma negativa a atuação do enfermeiro e seu cuidado com o paciente.
Identificar quais dificuldades o acadêmico de enfermagem encontra diante de sua prática ainda em construção e maturidade, pode permitir o reconhecimento de situações emocionais imprevisíveis que o docente no momento da prática não consiga perceber no acadêmico, $\mathrm{e}$ abrir um espaço de fala e escuta ativa com reflexão pode ajudá-lo a vencer os desafios que são experimentados diante das complexas situações do trabalho.

\section{REFERÊNCIAS BIBLIOGRÁFICAS}

Araújo, E. S. C., e Vieira, V. M. O. (2013). Práticas docentes na saúde: Contribuições para uma reflexão a partir de Carl Rogers. Revista Semestral da Associação Brasileira de Psicologia Escolar e Educacional, 17(1), 97-104.

Assad L. G., e L Viana L. O. (2003). Saberes práticos na formação do enfermeiro. Revista Brasileira de Enfermagem, 56(1), 44-47.

Casassus, J. (2009). Fundamentos da educação emocional. Brasília: Unesco Liber Livro Editora.

Cunha, T. A. A. (2013). Função das Emoções. Lisboa: Blog Oficina de Psicologia.

Cury, A. J. (2003). Pais brilhantes professores fascinantes. Rio de Janeiro: Editor Sextante.

Giannini, D. T., e Afonso, D. H. (2012). Construção colaborativa de um manual: Estratégia no processo ensino e aprendizagem na residência. Anais do Congresso de Avanços Tecnológicos em Saúde e Educação, Rio de Janeiro.

Goleman, D. (2012). Inteligência Emocional. Rio de Janeiro: Editora Objetiva.

Gomes, J. E. A. (2013). A relação entre afeto e aprendizagem: A partir do sentir e do pensar. Disponível em http://www.revista.ulbrajp.edu.br/ojs/index. php/actabrasileira/article/viewFile/287/23

Pizzol, A. D. (2013). Emoção e sentimento. Disponível em http://www.coladaweb.com/psicologia/emocao-esentimento

Schafranski, M. D. (2005). A educação e as transformações da sociedade. Revista Letras e Artes, 13(2), 101112. 